histories of the various sufferers from war neurosis convinced him that in the overwhelming majority of the cases there was definite evidence of the pre-existing functional instability of the nervous system. He predicted that an investigation into the physiological activity of the mechanisms of the motor system in such cases would reveal functional abnormalities, and work done in his laboratory from the point of view of the physiological psychologist certainly tended to support this view. Mott considered, then, that a neurosis was the response of an abnormally constituted organism to environmental stress which could be safely encountered by the normal individual, and he looked for such abnormalities of function rather in the emotional mechanisms and the various glandular organs that subserve them than in the higher nervous strata.

These views on the pathogenesis of the psychoses and neuroses are only now beginning to make themselves felt. At the time at which they were published, students of psycho-pathology, owing to a curious confusion of thought, seemed to have regarded the formulation of the anatomical and physiological disturbances found in the psychoses as an attempt to translate thought into terms of nervous mechanism. The real importance of this work is that it enables us to build up a pathology for the psychoses on the lines that have already been firmly established for the various toxæmic psychoses and for syphilitic insanity.

In the actual study of disorders of conduct Mott followed the methods of the less extreme school of behaviourism. He thoroughly distrusted the results of the various schools of psycho-analysis on methodological grounds, but he did not consider that his discoveries on the pathology of the nervous system had any direct bearing on the admissibility of their views. He considered that the majority of the pathological changes he had discovered in insanity are congenital, and instituted a very extensive inquiry into the genealogy of the cases in the London mental hospitals. As one of the fruits of his investigation he enunciated the "Law of Anticipation," in accordance with which the onset of the psychotic symptoms appears earlier in the successive generations of a degenerate family, and thus ultimately, owing to the production of infertile juvenile psychotics, the tainted stock disappears. He had more faith in the efficacy of this natural method for the elimination of the mentally unfit than in segregation or sterilisation. He pointed out that in the earlier generations of an insane family the psychosis is as a rule not evident until after much damage has been done by the breeding of tainted progeny.

Mott's work in the field of hospital hygiene is less widely known, but it is in a great measure due to his energy and teaching that dysentery in mental hospitals is almost a thing of the past.

The great work that Mott did for the teaching of the scientific aspects of psychiatry constitutes one of his greatest services to society. He was fortunate in possessing the esteem and friendship of a great clinical psychiatrist, Dr. Henry Maudsley, and when Maudsley proposed to found a hospital for the investigation and treatment of the early forms of mental disease, it was in order that it should be under the supervision of
Mott that he gave the necessary endowments to the London County Council. After many years of difficulty, the Maudsley Hospital for Early Mental Diseases was opened at Denmark Hill, and the Central Pathological Laboratory was transferred there from Claybury. It was here in the concluding years of his service as pathologist to the London Mental Hospitals that Mott instituted a school of psychiatrical medicine, one of the functions of which is to prepare the younger psychiatrists for the examination for the Diploma of Psychological Medicine, which has been instituted thanks to his efforts. Mott continued to teach enthusiastically in the Maudsley Hospital to the end, and acted as the director of a similar school of psychiatry in Birmingham, and he was on a visit thither when he had the cerebral seizure from which he died.

Mott was at the disposal of any one who sought his advice, and did much to assist younger men by suggestions and criticism. He was possessed of a sturdy common sense and preserved to advanced years a keen scientific acumen combined with a phenomenal receptivity for new views and facts. He was a man of wide culture, and his great kindliness and sincerity endeared him to all.

\section{Sir Henry Morris, Bart.}

Sir Henry Morris, who did more than any man of his time to open up the field of renal surgery, died in London on June 14 in his eighty-third year. On February II, I880, when he had become full surgeon on the staff of Middlesex Hospital, he removed a stone from the kidney of a patient, this being the first time that a deliberate operation had been performed for such a purpose. The operation was successful, and has become the type of a procedure now adopted by surgeons all the world over. When he gave Hunterian Lectures at the Royal College of Surgeons in 1898 , he was able to cite the results he had obtained from 267 operations carried out on the kidney. It is true that Gustav Simon of Heidelberg performed the first operation for the removal of a diseased kidney in 1869 , and that this operation had been frequently and successfully repeated before $\mathbf{I} 880$, but it was Morris who demonstrated that one of the commonest of disorders from which the human kidney suffers-the presence of renal concretions--can be safely cured by surgical procedure.

Sir Henry Morris was, however, a general surgeon in the best sense of the term and contributed to all branches of surgical art. He came of Welsh ancestry; his grandfather was a surgeon in Oswestry, and his father in Petworth. He was dark in hair and complexion, and massively framed in head, body and limbs, a good exemplification in the flesh of the type which $\mathrm{Mr}$. "Punch" has chosen to represent as "John Bull." He was a man of decided opinion, resolute in his policy, never afraid of opposition, and public-spirited to a high degree--often seeking the columns of the Times to guide opinion in educational, medical, social and political matters.

Epsom College and the University of London provided the opportunities of Sir Henry Morris's education, and he repaid both by giving them his unstinted services; he took an abiding interest in the welfare of

$$
\text { NO. 2956, VOL. I I } 7 \text { ] }
$$


Epsom College, acting as its treasurer for many years. His medical education was obtained at Guy's Hospital, but his life's work was spent in the wards of Middlesex Hospital, to which he became assistant surgeon in $187 \mathrm{x}$. There he did much to direct attention to the urgent need of research into the nature of cancer, and took an active part in founding the Imperial Cancer Research Fund.

Sir Henry Morris was also an anatomist. He lectured on human anatomy in the Medical School of Middlesex Hospital, and in 1893 edited a very successful "Treatise on Human Anatomy." An earlier work on the "Anatomy of Joints" is still a book of reference ; it contains many original observations.

In $x 893$ Sir Henry was elected to the council of the Royal College of Surgeons of England, serving as president for three years, I906, I907, 1908, a baronetcy being conferred on him then. He delivered the Hunterian Oration in 1909 , in which he compared the respective merits of the inductive and deductive methods of philosophy. He served on the General Medical Council, becoming treasurer to that body, and in I9Io was elected president of the Royal Society of Medicine. He was one of the outstanding figures in modern surgery, and a leading authority on medical education.
$W_{E}$ regret to announce the following deaths :

Prof. E. Babák, professor of physiology and general biology in the Masaryk University and Veterinary School in Brno, known for his work on the regulation of respiratory movements and also on the influence of endocrine glands on amphibian metamorphosis, on May 29, aged fifty-three years.

Prof. J. J. Flather, head of the department of mechanical engineering at the University of Minnesota and vice-president in 1902 of Section D of the American Association for the Advancement of Science, on May I4, aged sixty-three years.

Dr. C. Hering, a pioneer in electro-chemistry, who was one of the founders of the American Electrochemical Society in 1902 and in the same year began a movement which resulted in the foundation of Electrochemical Industry, on May ro, aged sixty-six years.

Prof. A. Magnin, formerly professor of botany and director of the Botanic Garden, University of Besançon, and a gold medallist of the French Geographical Society, aged seventy-eight years.

Prof. W. F. Shanks, professor of physiology in the University of Leeds since I923, and formerly lecturer in physiology in the University of Glasgow.

Prof. V. A. Steklov, professor of mathematics at the University of Leningrad and vice-president of the U.S.S.R. Academy of Sciences, on May 3o, aged sixty-one years.

\section{News and Views.}

Sitring in committee on the Finance Bill on June $2 \mathrm{I}$, the House of Commons rejected a clause moved by Mr. Withers (University of Cambridge) providing that a university, a college, or hall in a university, a public school, and any educational institution receiving a Government grant, should be exempt from income-tax in respect of any profits forming part of its income which were applicable to educational purposes only. The Chancellor of the Exchequer opposed the motion, though he stated that he was not satisfied with the present state of the law on the subject of the exemption of ' charities' exempt from income tax. The motion arose on the decision recently given by the House of Lords that a public school making a surplus is liable to taxation as earning profits, but the general question is closely related to the letter from the president and the treasurer of the Chemical Society which appeared in our issue of June 19 and their further letter in this present issue.

Those engineers who hold that the concentration and standardisation of electrical power supply in Great Britain is the best policy to adopt, and are weary of the somewhat fruitless discussions on points of administration taking place during the Committee stage of the present Government Bill, will now be able to point to the ever-growing electrification of Germany in support of their views. Plans have already been made for the inter-connexion of the existing power stations in Germany by overhead 'feeders' on a gigantic scale. In the past the production of electrical power in Germany has developed on individualistic lines. The largest power works belong to the Reich, which produces more than a thousand million units per annum solely for profit.
There are very many stations, however, of much smaller size which are very uneconomical. In some cases they burn peat fuel, and supply only a few hundred consumers. Owing to the great distances involved, it will be necessary to use very high pressures, and experiments are proceeding with insulators for use on lines with transmission pressures of 220 and $3^{80}$ kilovolts.

Two main schemes for electrification in Germany have been planned. The first proceeds from the water-power stations at the Vorarlberg in South Germany to Hamburg, and the second from the same source through the Central German lignite fields and Berlin to East Prussia. A length of about ıoo kilometres from the Goldenbergwerk to the Wesel is now working at I ro kilovolts, but double this pressure will probably become the standard. As chains of insulators are used there is no difficulty about insulation. With these high pressures it is necessary to use overhead wires of large diameter, otherwise brush discharges-the so-called corona-appear on the wires and lead to a serious loss of power. The conductors therefore are generally made of aluminium and are hollow. Some of the cable manufacturers make the conductors of copper, the outer cylindrical shell being supported by a helix of copper tape wound inside the hollow. In California, 220-kilovolt transmission over 243 miles has been in successful operation for the last two years. The cables are of aluminium with a steel core and are supported by chains consisting of twelve insulators.

REPORTS have appeared recently in some of the newspapers of a new steel, described as ' $F$ ' steel, which was stated to have great advantages for structural

NO. 2956, VOL. I I 7] 